\title{
Facilitators and Barriers of Teachers' Use of Effective Classroom Management Strategies for Students with ADHD: A Model Analysis Based on Teachers' Perspectives
}

\author{
Anna Szép ${ }^{1, *(D)}$, Slava Dantchev ${ }^{2}{ }^{(}$, Martina Zemp ${ }^{2}{ }^{(0}$, Malte Schwinger ${ }^{3}{ }^{(}$, Mira-Lynn Chavanon ${ }^{1}$ \\ and Hanna Christiansen ${ }^{1}$ \\ 1 Clinical Child and Adolescent Psychology, Department of Psychology, University of Marburg, \\ 35032 Marburg, Germany; mira-lynn.chavanon@staff.uni-marburg.de (M.-L.C.); \\ hanna.christiansen@uni-marburg.de (H.C.) \\ 2 Clinical Child and Adolescent Psychology, Department of Clinical and Health Psychology, University of \\ Vienna, 1010 Wien, Austria; slava.dantchev@univie.ac.at (S.D.); martina.zemp@univie.ac.at (M.Z.) \\ 3 Educational Psychology, Department of Psychology, University of Marburg, 35032 Marburg, Germany; \\ malte.schwinger@uni-marburg.de \\ * Correspondence: anna.szep@uni-marburg.de
}

check for

updates

Citation: Szép, A.; Dantchev, S.;

Zemp, M.; Schwinger, M.;

Chavanon, M.-L.; Christiansen, H.

Facilitators and Barriers of Teachers'

Use of Effective Classroom

Management Strategies for Students with ADHD: A Model Analysis Based on Teachers' Perspectives.

Sustainability 2021, 13, 12843.

https://doi.org/10.3390/su132212843

Academic Editor: Adela García-Aracil

Received: 31 October 2021

Accepted: 17 November 2021

Published: 19 November 2021

Publisher's Note: MDPI stays neutral with regard to jurisdictional claims in published maps and institutional affiliations.

Copyright: (c) 2021 by the authors. Licensee MDPI, Basel, Switzerland. This article is an open access article distributed under the terms and conditions of the Creative Commons Attribution (CC BY) license (https:/ / creativecommons.org/licenses/by/ $4.0 /)$.

\begin{abstract}
Students with attention-deficit/hyperactivity disorder (ADHD) often experience schoolrelated difficulties. Although evidence-based classroom management strategies (CMS) are known to alleviate such problems, they are rarely implemented. The current study examined whether a path model including variables influencing the use of effective CMS developed by top-down methods can be replicated utilizing an open science method. An extended model including class size and experience with children with ADHD was also calculated. We further explored prominent implementation barriers. $N=336$ in-service teachers completed an online survey. Perceived effectiveness, training on ADHD, perceived disruption, and affiliation with primary/special educational needs schools were important variables associated with the use of CMS. While class size was not correlated with the use of CMS, experience mediated by training revealed an indirect association with it. Class size, lack of time, and many students with disabilities were the most frequently reported implementation barriers. The implementation of effective CMS could thus be mainly enhanced by improving how effectiveness is perceived and by engaging teachers in ADHD-specialized training. Preparing teachers in how to cope with potential barriers should also be considered.
\end{abstract}

Keywords: ADHD; classroom management strategies; school; intervention; implementation barriers; open science; training; experience

\section{Introduction}

Attention-deficit/hyperactivity disorder (ADHD) is a chronic neurodevelopmental disorder affecting around $5 \%$ of school-aged children. It is characterized by developmentally inappropriate levels of inattention, hyperactivity, and impulsivity, which lead to functional impairments at home and in peer and educational contexts [1]. Students with ADHD carry an increased risk of severe school-related impairments including elevated rates of grade retention, academic underachievement, placement in special education classes, suspension, and school expulsion [2,3]. First-line treatment methods such as pharmacological interventions and (cognitive) behavioral therapy (or both) have proven to be effective in reducing ADHD core symptoms, but seem limited in terms of academic functioning [4]. Effective classroom management strategies (CMS) such as changing a student's seating location, daily-report cards, praise, ignoring disturbing behavior, on the other hand, have been proven to effectively improve classroom behavior and to a smaller extent, the academic performance of students with ADHD [5,6]. Thus, applying evidence-based interventions in schools is one of the most sustainable ways to help students with ADHD to 
cope with academic difficulties and subsequently improve their quality of life. Furthermore, applying evidence-based interventions in schools for students with ADHD is an important step to realize one of the sustainable developmental goals for education, namely providing an inclusive and effective learning environment for all [7]. The identification of factors influencing the uptake of CMS in schools, therefore, has important implications in reaching this goal. Nevertheless, despite the scientific evidence of their effectiveness, CMS are rarely implemented in classrooms [8,9]. Surprisingly, the reasons for this science-practitioner gap have not been widely investigated.

Based on the Theory of Planned Behavior (TPB; [10]), the ViolEx model [11,12], and literature review, Strelow et al. $[13,14]$ recently proposed a model that maps factors influencing teachers' intention to use effective CMS and also tested it first on pre-service and then slightly modified on in-service teachers $[13,14]$. The study found that perceived effectiveness of CMS, attitude toward students with ADHD, individual stress through students' ADHD behavior, teachers' affiliation with primary or special educational needs (SEN) schools, knowledge of ADHD, female sex, perceived behavioral control, and certain personality traits (e.g., extraversion, stress reactivity) were related to in-service teachers' intention to use effective CMS [14].

Of these factors, perceived effectiveness of CMS was particularly strongly associated with the intention of in-service teachers to apply CMS, suggesting that the belief that a specific intervention will work is crucial in implementing an intervention with in-service teachers [14]. This association was also confirmed with pre-service teachers [13], and replicated with preand in-service teachers in Austria [15]. The link between the perceived effectiveness of CMS and the actual use thereof has also been demonstrated elsewhere [16-18].

Students with ADHD often display overly disruptive behaviors in the classroom [19], making the teaching experience difficult and stressful $[20,21]$. Higher individual stress through students' ADHD-typical behavior seemed to directly strengthen the intention of in-service teachers to use effective CMS [14]. While this positive association between stress induced by ADHD typical behavior and applying effective CMS was confirmed by a study examining Austrian pre- and in-service teachers [15], a German study examining pre-service teachers detected no association between the two variables [13]. Comparable stress values across the three studies $(M=3.18$, [13]; $M=3.28$, [14]; $M=3.19,[15])$ and the fact that the Austrian sample largely consisted of in-service teachers (84.4\%) suggests that higher individual stress is only associated with more frequent effective CMS use among in-service but not pre-service teachers. In all three studies, stress induced by ADHD typical behavior was captured using the same single item, so conceptual replication with a sounder assessment is warranted.

The model analysis with in-service teachers indicated an indirect association between teachers' knowledge about ADHD and their use of effective CMS mediated through its perceived effectiveness [14]. This suggests that teachers with more knowledge about ADHD have more positive beliefs about the effectiveness of CMS and are therefore more likely to implement them. However, in both the study examining pre-service teachers [13] and the one conducted with Austrian pre- and in-service teachers [15], knowledge was directly and indirectly related to the intention to use CMS. Nevertheless, all three studies suggest that increasing teachers' knowledge on ADHD is a key factor in enhancing their ability to implement effective CMS [22]. For example, specialized training programs are known to be efficacious in increasing in-service teachers' knowledge about ADHD [23-25].

School type is another factor influencing the implementation of effective CMS, with primary and special educational needs (SEN) school teachers utilizing effective CMS more often than secondary school teachers $[13-15,18,26]$. There are several reasons for this finding. First, the former are usually more knowledgeable about ADHD [27,28]. Moreover, they have been reported to undergo more training on working with students with special needs [29]. Interestingly, the same studies describe sex differences, namely that more females teach in primary than secondary schools. Thus, female sex may interact or drive the influence of school type on using CMS $[18,26]$. Strelow et al. [14] found that these two 
factors contributed uniquely to the intention to use effective CMS. Female sex only exerted an indirect effect mediated by perceived effectiveness, while being affiliated with primary and SEN schools revealed both direct and indirect effects [14]. As no other relevant study on sex differences on this topic was found, more studies are needed to fill this research gap.

Another variable potentially accounting for the difference in the frequency of CMS use across school types is class size. Teachers find bigger classes to be especially difficult when it comes to implementing effective CMS [18,30]. Secondary school teachers are known to teach larger classes [31] and wish for smaller class sizes more often than teachers from other school types [18]. It is therefore conceivable that part of the effect that school type exerts on the use of effective CMS is attributable to its association with class size.

Beyond school type and sex, the model of in-service teachers was extended by adding the effect of work experience [14], which failed to contribute to the model [14,26,29]. Nevertheless, other studies suggest that not work experience per se, but rather experience with children with ADHD should be considered as an influencing variable when examining the teachers' use of intervention strategies [27,30,32]. Although no study has examined the effect of experience with children with ADHD on the application of effective CMS yet, a positive association with the teachers' confidence in their ability to accommodate students with ADHD [30], higher rates of self-study on the topic of ADHD [27,30], and more knowledge about ADHD [27,32] have been shown. These findings suggest that experience may exert an indirect effect on the use of effective CMS mediated by teachers' engagement in training focusing on ADHD.

The model of Strelow et al. [14] examined factors influencing the intention to use effective CMS. However, an intention does not necessarily lead to actual behavior [33]. Research on adult behavioral change suggests that preparing individuals for potential barriers to executing behavior helps to close this intention-behavior gap $[33,34]$. However, studies investigating barriers to effective CMS use for students with ADHD are lacking [35]. The few studies on the topic suggest that teachers tend to identify barriers inherent to the school environment or the intervention itself (e.g., the difficulty of managing students with ADHD while instructing the entire class) while they usually neglect factors related to their personal characteristics (e.g., knowledge about ADHD) [18,30,36]. Insufficient time to implement interventions appropriately within the classroom has been reported as the most frequent barrier $[18,30,37,38]$. The identification of common barriers would not just be beneficial for preparing teachers in how to cope with hindrances obstructing CMS use, but would also guide adjustments to existing CMS or the school environment, aiming to improve the contextual fit of interventions, helping make CMS more sustainable [36,39].

The protracted transition of evidence-based interventions into practice is not a new phenomenon [40]. While trying to shed light on the causes for impeding implementation, the Strelow et al. model $[13,14]$ was guided by theoretical considerations. This expertdriven, top-down approach might, however, be blind to factors central for individuals directly affected by and involved in the intervention [41]. To produce reliable and, more importantly, practicable knowledge, open and collaborative work involving non-scientists seems to be necessary. Utilizing open innovation principles and methods might therefore help to close the gap between science and practice [42]. One of these methods is to involve key stakeholders with first-hand experience in the scientific process. Key stakeholders can offer a unique perspective on the challenges they face and help to identify novel and relevant research questions that researchers might otherwise overlook. Moreover, involving key stakeholders in the research process enhances the probability of implementation $[43,44]$. Teachers can be considered as one of the main stakeholders when it comes to ADHD, as they play a pivotal role in many social, behavioral, and educational outcomes for students with ADHD [45]. The majority of psychological research about ADHD in the school context has so far failed to consider teachers' perceptions [35]. Including the teachers' perspective can provide new information about why teachers may perceive effective CMS as unsustainable in their teaching environment. 
The current study aims to bridge the gap between science and practice by taking an open-science approach. We applied crowdsourcing methodology to explore factors influencing the implementation of effective CMS and built a model with a bottom-up approach. In-service teachers were identified as central stakeholders within this process. A further aim of this study was to test whether expanding our replication model with potentially relevant variables (i.e., class size and experience with students with ADHD) would result in a better model fit. Finally, questions regarding barriers to CMS implementation were also investigated.

The primary objectives of this study were to answer the following questions:

1. Can the theory-driven path model of relevant factors associated with implementing effective CMS (i.e., perceived effectiveness of CMS, perceived disruption induced by specific behavioral problems associated with students with ADHD, formal or informal training in ADHD, school type, and sex) developed by Strelow et al. [14] via top-down methods be replicated utilizing bottom-up, open innovation methods?

Hypothesis 1 (H1). Perceived effectiveness, perceived disruption, and affiliation with primary/SEN schools are expected to be directly linked with more frequent CMS use, while participation in formal or informal training, female sex, and affiliation with primary/SEN schools are hypothesized to be indirectly associated with the use of CMS, all mediated by perceived effectiveness.

2. Does the inclusion of the variables class size and experience, measured by the number of children with ADHD currently instructed by the teacher improve the model fit compared to the original model?

Hypothesis 2 (H2). We assume that the model including the two additional variables class size and experience would result in better or at least equally good model fit while explaining more variance of the frequency of CMS use. We expect that perceived effectiveness, perceived disruption, affiliation with primary/SEN schools, experience with students with ADHD, and class size are directly linked with CMS use. We assume that CMS use is indirectly associated with female sex mediated by perceived effectiveness, with affiliation with primary/SEN schools mediated by both perceived effectiveness and class size, and with experience with children with ADHD mediated by participation in training whose indirect effect is mediated by perceived effectiveness.

3. What are the main barriers to implementing effective CMS according to in-service teachers, and do primary/SEN and secondary school teachers differ in how frequently they report them?

Given the lack of research in this area, we mainly analyzed the third research questions exploratorily.

\section{Materials and Methods}

\subsection{Sample}

The current sample stems from a bigger study analyzing the perspective of teachers as well as of the parents and students with ADHD on school-related difficulties. The current study focused on the teachers' perspectives. Our online survey started with $N=2230$ participants. Of those, a total of $n=1089$ participants completed the whole survey (state 2nd of October 2021; dropout rate 51.17\%). Out of these participants, $n=377(34.6 \%)$ were teachers, $n=540(49.6 \%)$ parents of children with $\mathrm{AD}(\mathrm{H}) \mathrm{D}, n=100(9.2 \%)$ children with $\mathrm{AD}(\mathrm{H}) \mathrm{D}$, and $n=72(6.6 \%)$ adolescents with $\mathrm{AD}(\mathrm{H}) \mathrm{D}$. The present study was based on the questionnaires filled out by teachers exclusively. Twenty-one teachers failed to provide their informed consent to the study and thus did not complete the questionnaire. Of the remaining $n=356, n=20$ had to be excluded due to missing values. Our final sample thus consisted of $N=336$ teachers aged on average $M=41.81(S D=11.29$; range $=21-73)$ years. A majority of participants $(n=292 ; 86.9 \%)$ identified themselves as female, $n=44$ 
(13.1\%) as male. These figures resemble the female-to-male teacher ratios from 2020/2021 in general education in Germany (female $=73.4 \%$; male $=26.6 \%$; [46]). In the total sample, $n=219(65.2 \%)$ identified themselves as primary or SEN school teachers, while $n=117$ $(34.8 \%)$ as secondary school teachers. Of all participating teachers, $n=265$ were working in Germany $(78.9 \%), n=67$ in Austria (19.9\%), and $n=4$ in Switzerland (1.2\%).

\subsection{Study Design}

A crowdsourcing approach embedded within the Open Innovation in Science framework of the Ludwig Boltzmann Gesellschaft (https: / / ois.lbg.ac.at/, accessed on 31 May 2021) was adopted to address the drivers and barriers impeding the implementation of evidence-based CMS in the context of ADHD. To gain a holistic understanding of the associated factors, four central stakeholder groups were considered: (1) teachers; (2) parents of children with $\mathrm{AD}(\mathrm{H}) \mathrm{D}$; (3) children with $\mathrm{AD}(\mathrm{H}) \mathrm{D}$; and (4) adolescents with $\mathrm{AD}(\mathrm{H}) \mathrm{D}$. We took a mixed-methods approach to generate a tailored questionnaire targeting the four stakeholder groups. First, postgraduate psychology students from the University of Marburg transcribed the qualitative data from interviews with individuals of the key stakeholder groups and used that data to generate an initial questionnaire. Information on this process is available at: https: / / www.uni-marburg.de/de/fb04/team-christiansen/ lehre/forschendes-lernen (accessed on 9 July 2021). Next, the questionnaire was revised together with postgraduate psychology students within the scope of a methodological seminar at the University of Vienna. To optimize the initial questionnaire, another set of focus group interviews with individuals representing the four stakeholder groups were conducted, this time focusing on the content of the preliminary questionnaire. Finally, the questionnaire was translated into a quantitative online survey designed using SoSci Survey software [47]. The current study relied only on the data collected from teachers via the online survey. The survey tailored to the teacher group consisted of 18 questions with diverse answer formats (e.g., visual analogue scales and Likert scales).

Given that the survey used in this study relied on interviews conducted with inservice teachers, some of the study variables examined by Strelow et al. [14] (which were not mentioned by those interviewed, e.g., personality traits or perceived behavioral control) were not assessed and thus could not be included in the model replication analyses. Other variables (e.g., sex and school type) were assessed as the same. Still, other variables were replaced by a construct resembling the one postulated by Strelow et al. [14]. Thus, individual stress through student's behavior was substituted with the variable perceived disruption through ADHD-typical behavior, and knowledge about ADHD was estimated by being engaged in formal or informal trainin on the subject of ADHD.

\subsection{Procedure}

Participants were recruited by collaborating with schools in Austria and Germany, via social media, and snowball sampling initiated by postgraduate students contributing to the study. Schools were selected randomly and contacted either via telephone or email and informed of the study rationale. A cover letter describing the aims of the study and the link to the online survey was sent out, and schools were asked to share the study information and link with their teachers. The study link was also distributed via social media using leaflets summarizing the study.

Participants from Germany were given the opportunity to partake in a raffle in which they could win either a Nintendo Switch or a voucher for a recreational experience of choice (worth about $350 €$ ). Three additional vouchers of choice in a value of $50 €, 20 €$, and $10 €$ were also raffled as an incentive to participate.

The first page of the online survey contained a short description of our study's aim and information about data collection and storage. Participation was voluntary and contingent on providing informed consent. The online survey was first sent out in June 2020 and data collection is still ongoing (Data analyzed in this study was accessed on 4 October). 
To account for the current SARS-CoV-2 pandemic, participants were asked to provide their answers based on normal school conditions and to disregard the exceptional circumstances relating to the ongoing pandemic. A written reminder was included at the top of each survey page.

\subsection{Measures}

\subsubsection{Sociodemographic Data}

Teachers completed a brief survey of general demographic information assessing their sex, age, the country they live in, the school type, the average size of the class they currently teach at (class size), and the number of children with ADHD they currently instruct (experience).

\subsubsection{Frequency of Use (FoU) and Perceived Effectiveness of CMS (Perceived Effectiveness)}

The self-reported frequency of CMS use was assessed via 11 items. The included strategies (e.g., structure, clear rules and consequences; reinforcing appropriate behavior) are recommended as effective strategies in supporting students with ADHD [5,6,48]. The original questionnaire consisted of twelve items, of which one (change of seating arrangement) had to be excluded due to low item-total correlation $(r=0.16)$. Teachers indicated their frequency of use on an 11-point visual analogue scale (VAS) ranging from never to very often. Values were transformed into an interval scale from 1 to 101 . The scale proved to be reliable $(\alpha=0.79)$.

CMS were further rated on their perceived effectiveness on an 11-point VAS ranging from ineffective to very effective (values between 1 and 101). One item (change of seating arrangement) had to be excluded due to a low item-total correlation $(r=0.20)$. The scale showed good internal consistency $(\alpha=0.83)$.

2.4.3. Perceived Disruption Induced by Specific Behavioral Problems Associated with Students with ADHD (Perceived Disruption)

Teachers rated the extent of the experienced disruption induced by specific behavioral problems associated with students with ADHD (e.g., talking out of turn, fidgeting). The original scale consisted of eight items, of which one (ostracizing classmates) was excluded due to a low item-total correlation $(r=0.06)$. Teachers indicated their level of disruption on an 11-point VAS ranging from not disrupting at all to very disrupting. Values were transformed into an interval scale from 1 to 101. The scale exhibited acceptable internal consistency $(\alpha=0.74)$.

\subsubsection{Teachers' Participation in Formal or Informal Training (Training)}

Teachers were asked whether they engaged in activities aiming to widen their knowledge about ADHD. Answers were recorded dichotomously (yes/no).

\subsubsection{Barriers of CMS Implementation and Support Needs}

Factors impeding CMS implementation were measured via a single question. Teachers could choose three out of the 15 barriers listed underneath the question (e.g., time constraints, lack of knowledge about interventions). An open-ended response field was also included. A maximum of three responses could be selected.

\subsubsection{Influence of the Special Conditions Due to the SARS-CoV-2 Pandemic}

To see whether the conditions caused by the SARS-CoV-2 pandemic influences the teachers' responses, participants were asked to report the extent to which they were able to ignore the COVID-19 situation and associated measures while answering the survey. Responses were given on a 5-point Likert scale. Higher scores indicated feeling more able to disregard the COVID-19 situation. 


\subsection{Statistical Analyses}

All analyses were conducted using SPSS ${ }^{\circledR}$ (V. 26.0, IBM Corp., Amok, NY, USA) [49] and Mplus 8.4; Muthén \& Muthén, Los Angeles, CA, USA [50]. To detect non-serious responders, the plausibility of the answers on the variables age and class size was analyzed by looking at the range of the two variables. The range of the variables was deemed plausible $\left(\operatorname{Min}_{\text {age }}=21 ; \operatorname{Max}_{\text {age }}=73 ; \operatorname{Min}_{\text {class }}=6 ;\right.$ Max $\left._{\text {class }}=34\right)$. To detect careless responders, measures of response time were analyzed. First, the absolute time spent to complete all relevant pages of the questionnaire (without filter options) were analyzed for outliers. On average, participants took $M=64.85 \mathrm{~min}(S D=617.19)$ minutes to complete the survey. Two outliers $(M=10927,92 ; M=2681.48)$ were identified. Given that these two participants spent significantly more and not less time answering the questionnaire compared to other responders, which might be explained by low experience with online surveys or short breaks during responding, they were not considered careless responders. An index for relative completion speed for each page was also computed [51] by dividing the median of the sample's page completion time by the individual's completion time. We used the median due to the extreme skewness of data (skewness $=17.12$; kurtosis $=306.94$ ). The highest average speed factor was 7.76, indicating that this participant completed the pages eight times faster than a typical participant. As no clear cut-off points for excluding participants based on their completion time exist, and other possible explanations (e.g., skipping a page; high expertise for the topic of ADHD) for this high speed factor exist, the exclusion of this participant was not seen as justified.

\subsubsection{Missing Data Analysis}

Across all variables included in our main analyses, 9.0\% of the data were missing. Little's MCAR test conducted on study variables indicated that the pattern of missing values was not completely random $\left(\chi^{2}(568)=644.86 ; p=0.014\right)$. To test whether individuals with missing values systematically differed from those with none, we conducted a dropout analysis. Dummy variables for each variable with missing values were computed and group means of model and demographic (age) variables were compared with t-tests for continuous and with chi-square tests for categorical variables. Since most analyses contained an expected frequency below 5 , additional Bayes factors were calculated. The analyses suggested a missing at random (MAR) pattern. Individuals with missing values on the perceived effectiveness variable revealed significantly lower values on the perceived disruption variable than individuals without missing values $(t(4.136)=2.78 ; p=0.05$; Cohen's $d=0.18$ ). Moreover, individuals without training were slightly more likely to have a missing value on the FoU variable; $\left(\chi^{2}(1)=8.00 ; p=0.05 ; \mathrm{BF}_{01}=3.68\right)$. We thus employed full information maximum likelihood (FIML) estimation to manage missing data, which generates accurate parameter estimates and standard errors for MAR data [52].

\subsubsection{Path Model Analysis}

First, inter-correlations between study variables were computed. Linear path analysis with Mplus 8.4 was used to partly replicate the model of Strelow et al. [14]. Perceived disruption, training, sex, and school type were specified as exogenous variables, perceived effectiveness as a mediating variable, and FoU as the outcome variable. Figure 1 depicts the final model to examine the first research question.

To test the second research question, we also ran an extended path analysis with class size and experience as additional variables with direct effects on FoU. In this analysis, class size and training were considered as mediating variables in addition to perceived effectiveness. The associations between the remaining variables were included in the model the same way as assumed in the first model (see Figure 2). 


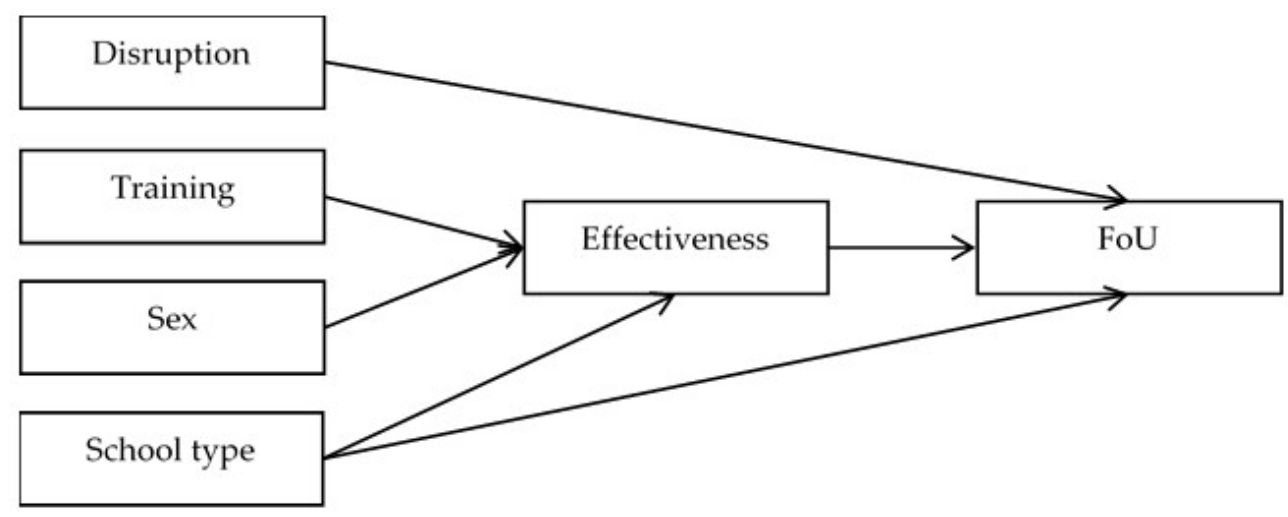

Figure 1. Hypothetical path model predicting the use of effective CMS. FoU = Frequency of CMS use.

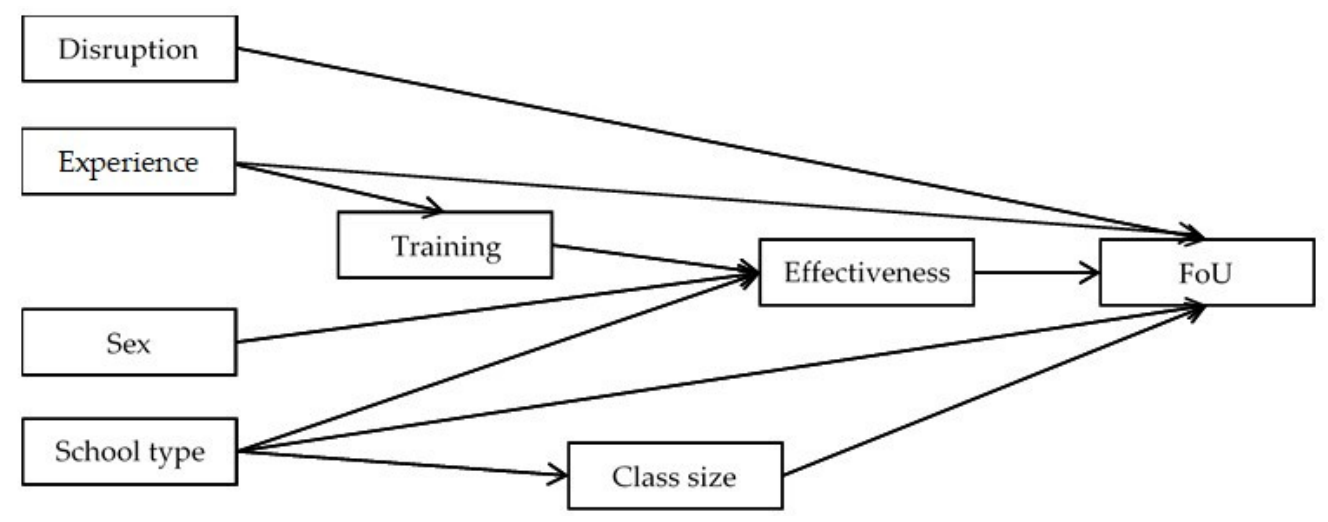

Figure 2. Hypothetical extended path model predicting the use of effective CMS.

The following fit indices were used to determine model fit: chi-square $\left(\chi^{2}\right)$, the comparative fit index (CFI), the Tucker-Lewis index (TLI), the standardized root mean square residual (SRMR) index, and the root mean square error of approximation (RMSEA). For a good model fit, the chi-square test should be non-significant $(p>0.05)$, CFI and TLI at least $>0.95$, and RMSEA and SRMR values less than < 0.05 [53]. To facilitate the selection of a superior model, we additionally computed the Akaike information criterion (AIC; [54]) and Bayesian information criterion (BIC; [55]). The model with lower values on the two selection criteria is considered to be superior [56]. To counter for non-normal distribution and heteroscedasticity, bootstrapping with 10,000 iterations and bias-corrected confidence intervals were used for the analysis.

\subsubsection{Exploratory Analyses}

To answer our third research question, the frequency of perceived implementation barriers to CMS use were computed separately for primary/SEN and secondary teachers. The two groups were also compared along with their reported frequencies using chi-square tests. Additional to traditional significance values, a Bayes Factor $\left(\mathrm{BF}_{01}\right)$ was also computed as further evidence for the detected group differences.

\section{Results}

Teachers reported feeling very able to ignore the unusual COVID-19 related situation while answering the questionnaire $(M=4.22$; [possible range 1-5]; $S D=0.82)$. Descriptive statistics and intercorrelation coefficients between study variables are depicted in Table 1. 
Table 1. Descriptives and intercorrelations among study variables.

\begin{tabular}{|c|c|c|c|c|c|c|c|c|c|c|c|}
\hline & $n$ & $M^{\mathrm{d}}$ & $S D$ & 1 & 2 & 3 & 4 & 5 & 6 & 7 & 8 \\
\hline 1. FoU & 344 & 759.35 & 144.00 & - & & & & & & & \\
\hline 2. Effectiveness & 349 & 772.47 & 160.32 & $0.54^{* *}$ & - & & & & & & \\
\hline 3. Disruption & 347 & 483.06 & 104.49 & $0.15^{* *}$ & -0.02 & - & & & & & \\
\hline 4. Sex ${ }^{a, e}$ & 354 & 0 & - & $-0.17^{* *}$ & -0.08 & -0.09 & - & & & & \\
\hline 5. School type ${ }^{b, e}$ & 349 & 0 & - & $-0.26^{* *}$ & -0.14 * & -0.14 * & $0.27^{* *}$ & - & & & \\
\hline 6. Training ${ }^{\mathrm{c}, \mathrm{e}}$ & 354 & 1 & - & $0.30^{* *}$ & $0.14^{* *}$ & -0.02 & $-0.11^{*}$ & -0.07 & - & & \\
\hline 7. Age & 354 & 42.01 & 11.44 & $0.11^{* *}$ & 0.07 & -0.06 & 0.01 & -0.02 & $0.26^{* *}$ & - & \\
\hline 8. Experience & 338 & 1.67 & 2.27 & $0.12 *$ & 0.09 & -0.01 & $0.15^{* *}$ & $0.16^{* *}$ & $0.23 * *$ & $0.11 *$ & - \\
\hline 9. Class size & 351 & 20.68 & 4.70 & $-0.16^{* *}$ & 0.17 & -0.04 & $0.15^{* *}$ & $0.43^{* *}$ & -0.08 & -0.07 & 0.04 \\
\hline
\end{tabular}

${ }^{\mathrm{a}} 0=$ female and $1=$ male. ${ }^{\mathrm{b}} 0=$ primary and SEN school and $1=$ secondary school. ${ }^{\mathrm{c}} 0=$ no engagement in training and $1=$ engagement in training. ${ }^{\mathrm{d}}$ Dichotomous variables $(4,5,6)$ mode instead of $M .{ }^{\mathrm{e}}$ Association between dichotomous variables Phi coefficient instead of Pearson $\mathrm{r} .{ }^{*} p<0.05 .{ }^{* *} p<0.01$. FoU $=$ Frequency of Use.

\subsection{Path Analysis of the Replication Model}

Partially replicating the path model postulating variables influencing the FoU of effective CMS by in-service teachers from the Strelow et al.'s study [14] revealed an unsatisfactory model fit $\left(\chi^{2}(3)=29.62, p<0.01 ; R^{2}\right.$ FoU $=0.35, p<0.001 ; R^{2}$ effectiveness $\left.=0.03, p=0.12\right)$ with unsatisfactory model fit indices $(\mathrm{CFI}=0.84 ; \mathrm{TLI}=0.53$; $\mathrm{RMSEA}=0.16$; $\mathrm{SRMR}=0.07$; $\mathrm{AIC}=8436.77 ; \mathrm{BIC}=8474.96)$. We slightly modified our replication model guided by theoretical considerations (the original model on pre-service teachers [13] and the replication study by Zemp et al. [15]) and modification indices. Training was now postulated to have a direct effect on the FoU beyond its indirect effect. Model fit indices now indicated an excellent model fit $\left(\chi^{2}(2)=1.40 ; p=0.50 ; \mathrm{CFI}=1.00 ; \mathrm{TLI}=1.00 ; \mathrm{RMSEA}<0.01 ; \mathrm{SRMR}=0.02\right.$; $\mathrm{AIC}=8410.57 ; \mathrm{BIC}=8452.56)$ and explained $40.4 \%$ of the variance in the FoU $(p<0.001)$. FoU was directly affected by perceived effectiveness $(\beta=0.49 ; p<0.001 ;[95 \%-\mathrm{CI}=0.39$, $0.57])$, perceived disruption $(\beta=0.16 ; p<0.001 ;[95 \%-C I=0.07,0.24])$, affiliation with primary and SEN schools $(\beta=-0.16 ; p<0.001 ;[95 \%-\mathrm{CI}=-0.25,-0.06])$ and training $(\beta=0.23 ; p<0.001 ;[95 \%-\mathrm{CI}=0.15,0.32])$. The model did not explain a significant proportion of the variance in perceived effectiveness $\left(R^{2}\right.$ effectiveness $\left.=0.03 ; p=0.12\right)$. Only training was directly associated with perceived effectiveness $(\beta=0.13 ; p=0.01 ;[95 \%-\mathrm{CI}=0.02$, $0.23])$. Sex $(\beta=-0.04 ; p<0.54 ;[95 \%-\mathrm{CI}=-0.16,0.08])$ and school type $(\beta=-0.11 ; p=0.05$; $[95 \%-\mathrm{CI}=-0.25,0.01])$ did not influence perceived effectiveness significantly. The indirect effect of perceived effectiveness as a mediator in the relationship between training and FoU was significant $(\beta=0.06 ; p=0.002 ;[95 \%-\mathrm{CI}=0.01,0.12])$, while the relationship between sex and FoU ( $\beta=-0.02 ; p=0.55$; $[95 \%-\mathrm{CI}=-0.08,0.04])$ as well as between school type and FoU $(\beta=-0.05 ; p=0.05 ;[95 \%-C I=-0.11,0.01])$ was not mediated by perceived effectiveness.

According to these results, sex is neither directly nor indirectly related to FoU. Thus, in line with the principle of parsimony, we modified our model and ran another path analysis excluding sex from our model. Model fit indices indicated an excellent model fit with slightly better model indices $\left(\chi^{2}(1)=0.43, p=0.51 ; \mathrm{CFI}=1.00 ; \mathrm{TLI}=1.00\right.$; RMSEA $<0.01$; $\mathrm{SRMR}=0.01 ; \mathrm{AIC}=8433.93 ; \mathrm{BIC}=8472.13)$. The more parsimonious model explained $40.1 \%$ of the variance in the FoU $(p<0.001)$. FoU was still directly associated with perceived effectiveness ( $\beta=0.49 ; p<0.001 ;[95 \%-C I=0.39,0.57])$, perceived disruption $(\beta=0.15$; $p<0.001 ;[95 \%-\mathrm{CI}=0.07,0.24])$, affiliation with primary or SEN schools $(\beta=-0.16 ; p<0.001$; $[95 \%-\mathrm{CI}=-0.25,-0.07])$, and training $(\beta=0.23 ; p<0.001 ;[95 \%-\mathrm{CI}=0.15,0.32])$. The model did not clarify variance on perceived effectiveness $\left(R^{2}\right.$ effectiveness $\left.=0.03 ; p=0.11\right)$. Both training $(\beta=0.13 ; p=0.01 ;[95 \%-\mathrm{CI}=0.03,0.23])$ and school type $(\beta=-0.12 ; p=0.03$; $[95 \%-C I=-0.22,-0.01])$ were significantly linked with perceived effectiveness in this model. The association between training and FoU ( $\beta=0.06 ; p=0.002 ;[95 \%-\mathrm{CI}=0.01$, $0.12])$ and between school type and FoU $(\beta=-0.06 ; p=0.03 ;[95 \%-\mathrm{CI}=-0.11,-0.01])$ was 
mediated by perceived effectiveness. The final path model with standardized coefficients is depicted in Figure 3.

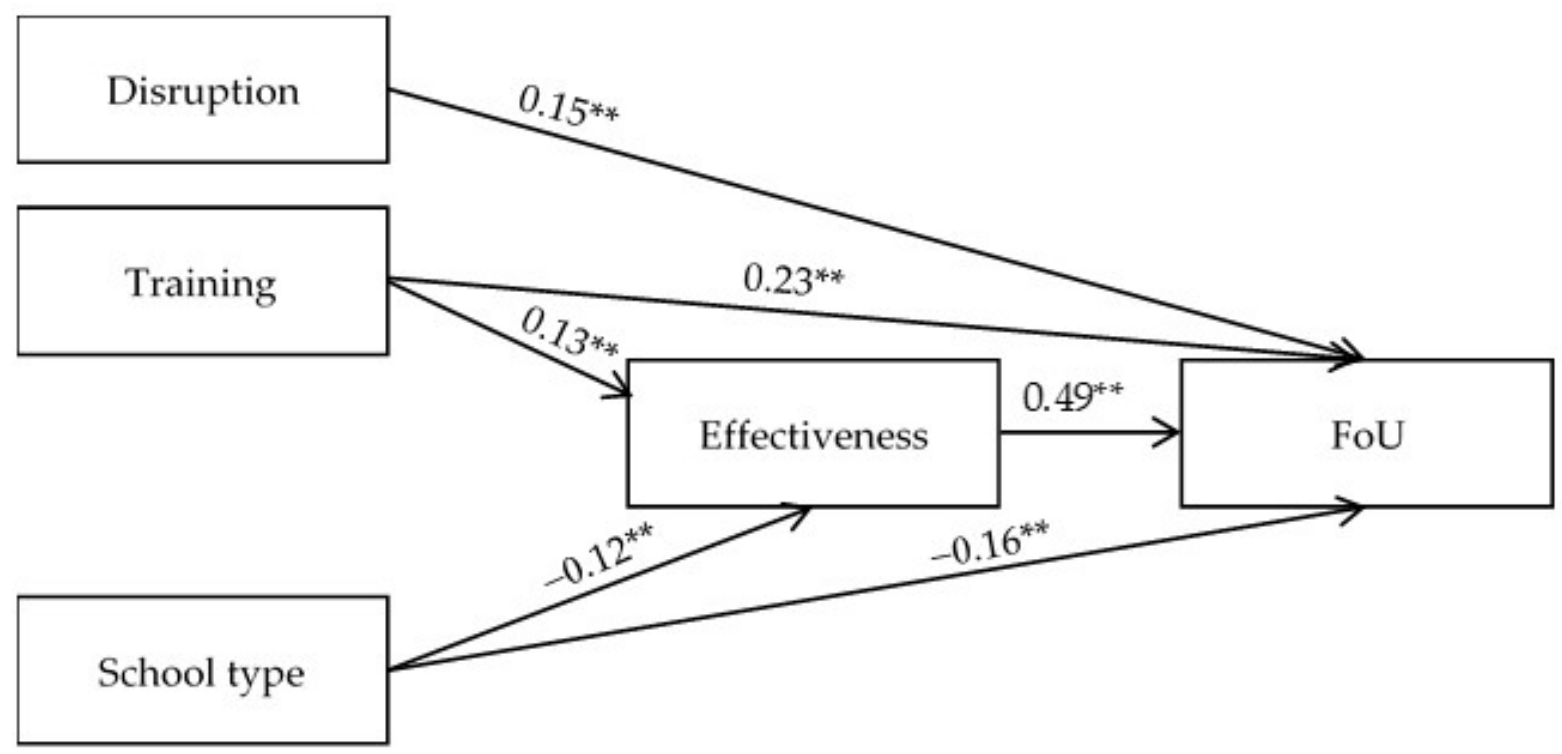

Figure 3. Final path model predicting the use of effective CMS $(N=337) .{ }^{* *} p<0.01$.

\subsection{Path Analysis of the Extended Model}

We adjusted our extended model analysis according to the information gleaned from the two analyses beforehand. We therefore excluded sex, and ran the analysis with training, having both a direct and indirect effect on FoU. Analysis of the extended model resulted in excellent model fit $\left(\chi^{2}(8)=7.67, p=0.47 ; \mathrm{CFI}=1.00\right.$; TLI $=1.00$; RMSEA $<0.01$; SRMR = 0.035; AIC $=10523.33$; $\mathrm{BIC}=10591.66)$ with fairly similar model fit indices except for indices of model selection criteria. FoU's variance explanation shrank to $38.8 \%(p<0.001)$. The direct effect of the two variables on FoU was not significant $\left(\beta_{\text {class size }}=-0.02 ; p=0.67 ;[95 \%\right.$ $\left.\mathrm{CI}=-0.11,0.07] ; \beta_{\text {experience }}=0.07 ; p=0.07 ;[95 \%-\mathrm{CI}=-0.01,0.14]\right)$. The association between experience and training became significant $(\beta=0.23 ; p<0.001$; $[95 \%-C I=0.15,0.31]$ ). Experience explained $5.5 \%$ of the variance in training $(p=0.004)$. Furthermore, training significantly mediated the relationship between experience and FoU ( $\beta=0.05 ; p<0.001$; $[95 \%-\mathrm{CI}=0.03,0.09])$. Although school type clarified $18.2 \%$ of the variance in class size $(p<0.001 ; \beta=0.43 ; p<0.001 ;[95 \%-\mathrm{CI}=0.32,0.52])$, the effect of school type on FoU was not mediated by class size $(\beta=-0.01 ; p=0.68 ;[95 \%-C I=-0.05,0.03])$. The direct relationship between FoU and other model variables did not change meaningfully; effectiveness and training showed a slightly weaker relationship with FoU ( $\beta_{\text {effectiveness }}=0.48 ; p<0.001 ;[95 \%$ $\left.\mathrm{CI}=0.38,0.56] ; \beta_{\text {training }}=0.22 ; p<0.001 ;[95 \%-\mathrm{CI}=0.13,0.31]\right)$, while the association with school type became slightly stronger $\left.\beta_{\text {school type }}=-0.17 ; p<0.001 ;[95 \%-\mathrm{CI}=-0.28,-0.07]\right)$ and with perceived disruption remaining the same ( $\beta_{\text {disruption }}=0.15 ; p=0.001 ;[95 \%-\mathrm{CI}$ $=0.07,0.24])$. Results were approximately the same for variance explanation $\left(R^{2}=0.03\right.$; $p=0.14)$ and direct effects of perceived effectiveness $\left(\beta_{\text {training }}=0.13 ; p=0.02 ;[95 \%-\mathrm{CI}=0.02\right.$, $\left.0.23] ; \beta_{\text {school type }}=-0.11 ; p=0.04 ;[95 \%-\mathrm{CI}=-0.21,0.02]\right)$. The association between FoU and other variables mediated by perceived effectiveness resulted in approximately the same estimates $\left(\beta_{\text {training }}=0.06 ; p=0.02 ;[95 \%-C I=0.01,0.11] ; \beta_{\text {school type }}=-0.05 ; p=0.04\right.$; $[95 \%-\mathrm{CI}=-0.10,0.01])$. The final extended path model with standardized coefficients is depicted in Figure 4. 


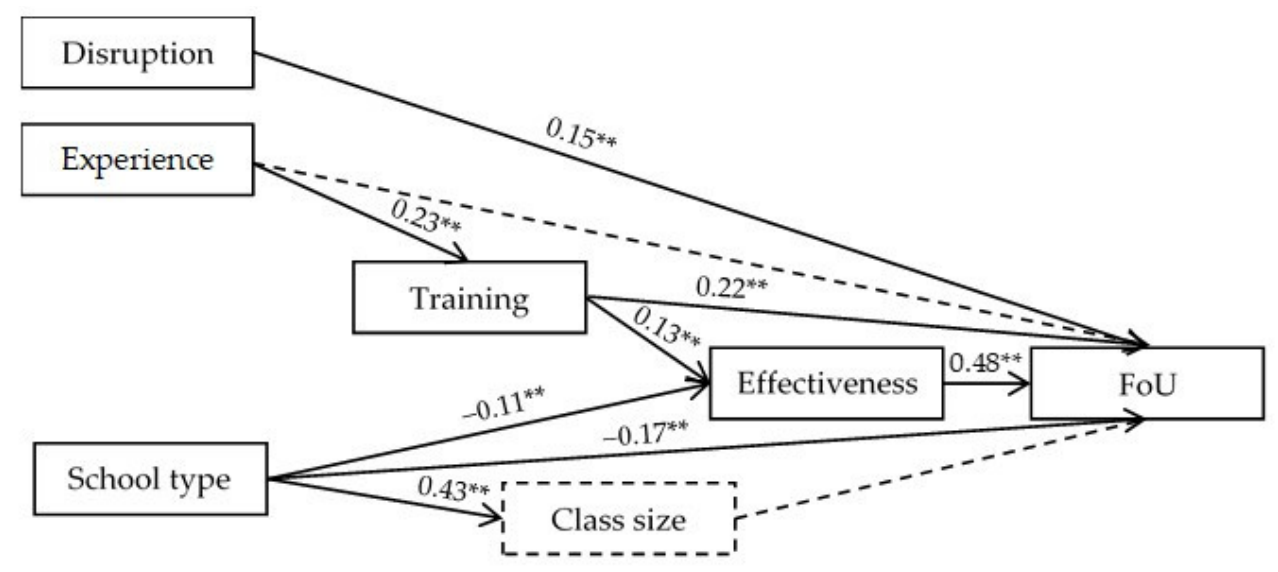

Figure 4. Extended path model predicting the use of effective CMS $(N=329)$. Dashed lines mark non-significant results. ** $p<0.01$.

\subsection{Exploratory Analyses}

The frequency of perceived implementation barriers to CMS use reported separately by primary/SEN and secondary teachers are depicted in Table 2. While having many students with disabilities is more difficult according to primary or SEN school teachers, complications regarding the meeting of joint arrangements about classroom management with other teachers seem to be more problematic for secondary school teachers. According to the chi-square test, poor cooperation with caregivers was reported more frequently by primary or SEN school teachers, the Bayes factor did not indicate much higher probability for the alternative hypothesis than for the null hypothesis.

Table 2. Frequency of perceived barriers to effective CMS implementation indicated by primary/SEN and secondary school teachers.

\begin{tabular}{|c|c|c|c|c|c|}
\hline Barriers to Effective CMS Implementation & $\begin{array}{c}\text { Primary/SEN } \\
\text { School Teachers }\end{array}$ & $\begin{array}{c}\text { Secondary } \\
\text { School Teachers }\end{array}$ & $x^{2}$ & df & $\mathrm{BF}_{01}$ \\
\hline Too many different teachers for one class & $23.8 \%$ & $30.3 \%$ & 1.76 & 1 & 0.41 \\
\hline $\begin{array}{l}\text { Missing joint arrangements with other } \\
\text { teachers about classroom management }\end{array}$ & $11.0 \%$ & $24.6 \%$ & $11.02 * *$ & 1 & 27.78 \\
\hline Lack of time & $37.4 \%$ & $44.3 \%$ & 1.54 & 1 & 0.40 \\
\hline Class size, too many students in one class & $57.7 \%$ & $57.4 \%$ & 0.01 & 1 & 0.19 \\
\hline Lack of cooperation with caregivers & $4.8 \%$ & $3.3 \%$ & 0.47 & 1 & 0.09 \\
\hline Poor cooperation with caregivers & $15.9 \%$ & $8.2 \%$ & $4.07^{*}$ & 1 & 0.99 \\
\hline No flexibility in everyday teaching & $18.1 \%$ & $22.1 \%$ & 0.84 & 1 & 0.23 \\
\hline $\begin{array}{c}\text { Too many students with disabilities in } \\
\text { one class }\end{array}$ & $50.7 \%$ & $35.2 \%$ & $7.61^{* *}$ & 1 & 8.55 \\
\hline $\begin{array}{l}\text { Group dynamics in the class make } \\
\text { individual support difficult }\end{array}$ & $15.9 \%$ & $13.1 \%$ & 0.47 & 1 & 0.17 \\
\hline Lack of knowledge about interventions & $7.9 \%$ & $9.0 \%$ & 0.12 & 1 & 0.11 \\
\hline $\begin{array}{l}\text { Insufficient knowledge transfer during } \\
\text { undergraduate studies }\end{array}$ & $6.6 \%$ & $7.4 \%$ & 0.73 & 1 & 0.10 \\
\hline Too few teachers in the educational system & $6.6 \%$ & $5.7 \%$ & 0.10 & 1 & 0.09 \\
\hline No consent from caregivers & $3.5 \%$ & $1.6 \%$ & 1.01 & 1 & 0.10 \\
\hline (Work)overload of teachers & $23.3 \%$ & $22.1 \%$ & 0.07 & 1 & 0.16 \\
\hline Lack of practical tools & $12.3 \%$ & $9.8 \%$ & 0.49 & 1 & 0.15 \\
\hline
\end{tabular}

${ }^{*} p<0.05 ;{ }^{* *} p<0.01 . N=349$.

\section{Discussion}

The current study aimed to examine factors associated with the use of effective CMS for students with ADHD. In doing so, we hoped to gain more insight into teachers' perspectives and provide information on the challenges teachers face while trying to apply 
effective interventions and to guide practitioners and future research alike on how to make CMS more sustainable in the school environment.

\subsection{General Discussion}

The first aim of this study was to test whether a path model containing variables associated with the use of effective CMS constructed by a top-down, theory-driven approach [14] could be replicated by applying a bottom-up open science method. The replication succeeded overall, with comparable associations of strength and few divergences from the original model.

In line with the Strelow et al. model [14], the perceived effectiveness had the strongest association with in-service teachers' application of effective CMS, underlining the importance of their perception of specific CMS. Consistent with our hypothesis, perceived disruption was positively associated with using effective CMS. This is also in line with Strelow et al. [14] and strengthens the assumption that feeling stressed or annoyed by ADHD-typical behavior directly motivates in-service teachers to apply effective CMS more frequently.

Training proved to be an important factor influencing the use of effective CMS. Contrary to Strelow et al. [14], training was not only indirectly associated and mediated through perceived effectiveness, but it also showed an additional direct effect on employing CMS. These findings are, however, consistent with the study on German pre-service [13] and Austrian pre- and in-service teachers [15] in that both found a direct and indirect association between knowledge about ADHD and using CMS. Nevertheless, given that the current study only examined in-service teachers, our results should be more congruent with Strelow et al. [14], who likewise included only in-service teachers, as opposed to the studies focusing on pre-service teachers. It is important to consider that knowledge was operationalized as formal or informal in-service training on ADHD in the current study. While training focused on ADHD is expected to result in more knowledge of ADHD [23-25], only a weak to moderate relationship between the two variables has been previously reported [32,57]. Training on ADHD might not necessarily lead to knowledge transfer, suggesting that the two constructs might not be comparable. Moreover, in-service teachers are expected to have more knowledge of ADHD than pre-service teachers [48]. However, it may also be that pre-service teachers rather hold more general ADHD-related knowledge (etiology, diagnostics, or prevalence) while teachers gaining knowledge through in-service training typically focus more on different intervention methods [28]. Beyond this, pre-service teachers, being less experienced, may not rate their intentions to use CMS as accurately as in-service teachers. It is therefore conceivable that more knowledge of pre-service teachers' about ADHD may lead to the conviction that applying effective CMS is imperative, enhancing their intention to use them, while in-service teachers might already have been discouraged by encountered barriers during their attempts to implement. Therefore, more knowledge about ADHD only seems to enhance in-service teachers' intention to use CMS provided they are entirely convinced that their efforts will bear fruit, hence they are only mediated by perceived effectiveness. Training that conveys more hands-on knowledge, however, could presumably help teachers to come up with specific strategies through which they can effectively support students with ADHD, making a direct association possible. The importance of the direct association between training and FoU is highlighted by the fact that our model resulted in unsatisfactory model fit indices without that direct path. Overall, our results indicate that formal or informal training on the topic of ADHD is the second most important variable influencing the frequency of applying effective CMS among the study variables we examined.

In our final model, after excluding sex, both direct and indirect effects of school type on the frequency of CMS use became significant, reinforcingfindings demonstrating that primary and special school teachers tend to apply effective CMS more frequently than secondary school teachers $[14,18,26]$. Secondary school teachers did not only use effective CMS less often-they also rated them less effective. This association might be attributable 
to primary school teachers' greater knowledge about ADHD [18,28]. This would suggest that educating secondary teachers about ADHD would positively influence their perception of effectiveness and the use of CMS. On the other hand, the current study identified no significant correlation between school type and training, indicating that secondary teachers do not participate in training less often than primary or SEN school teachers do. Thus, training itself might not suffice to increase secondary teachers' use of effective CMS.

Contrary to the assumption that the female sex is responsible for applying CMS more often than is being affiliated with primary or SEN schools [18,26], our study revealed no significant direct or indirect association between sex and using effective CMS, a result that contradicts the Strelow et al. model [14] and with research on general classroom management [36]. Nevertheless, studies on sex differences in this context are so scarce that assuming that teachers' sex does not influence their CMS use seems quite plausible, although more studies are needed to clarify this issue.

The second aim of the present study was to explore the effects of experience with children with ADHD and class size on the use of effective CMS. Our inclusion of these two variables resulted in an equally excellent model fit. Lower model selection criteria values suggest the model's superiority without the two additional variables. This is not that surprising, given that model selection criteria can be perceived as the formalization of Occam's razor inherently favoring a more parsimonious model with fewer parameters [58]. Furthermore, even though the extended model contained two additional variables, the amount of explained variance of CMS use was lower in this model, speaking for the superiority of the original, more parsimonious model. Nevertheless, our extended model's results have important implications worthy of exploration.

Class size was neither directly nor indirectly associated with applying effective CMS. This result is somewhat surprising, as class size has often been reported to be a prominent barrier to using effective CMS [18,35]. This finding is unexpected, particularly considering that teachers in our sample identified class size as the most frequent barrier to implementing CMS. This finding might suggest that although teachers perceive bigger classes as hindering interventions, they simultaneously appear capable of overcoming these barriers. Furthermore, contrary to our expectations, the indirect relationship of class size mediated through school type was non-significant, despite the strong association between class size and school type. Thus, the difference in class sizes between primary/SEN and secondary schools does not seem to explain the association between school type and CMS use. Future research is needed to disentangle why effective CMS are applied less frequently in secondary schools. Evidence-based CMS might fit better in the primary school context, where students are primarily taught by only one teacher. This assumption is partly supported by our study finding that secondary teachers named missing joint arrangements with other teachers more frequently as an implementation barrier. Clarifying this issue is central for providing sustainable help to students with $\mathrm{ADHD}$, considering that as the academic demands on students increase, their adequate behavioral support seems to decrease, resulting in poor academic outcomes and students with ADHD dropping out [2,3].

Experience demonstrated an indirect association with the use of CMS, mediated through training. This finding is partly in line with studies describing experience with children with ADHD as an important variable influencing the use of CMS [27,32,35]. In the current study, however, experience was only indirectly associated with FoU. Teachers instructing more children with ADHD were more likely to have been engaged in formal or informal training, which in turn increased their application of effective CMS. Thus, direct experience with children with ADHD, as studies have shown [27,30,32], seems to motivate teachers to seek solutions for how to manage children with ADHD effectively, and their use of CMS is increased through such knowledge gained by formal or informal training on ADHD. At this point, it is important to note that the current study operationalized experience as the number of children with ADHD currently instructed by teachers; we did not measure how many children with ADHD teachers have encountered during their entire teaching career. 
Our last aim was to expand on the knowledge of barriers to CMS implementation as perceived by teachers. Teachers experienced several barriers preventing effective CMS use. In line with published evidence, class size, time constraints, and too many students with disabilities in one class were the three most prominent barriers reported by primary/SEN and secondary school teachers $[18,30]$. The majority of reported barriers did not differ in their frequency between primary and secondary teachers except for having too many students with disabilities in one class, which primary or SEN school teachers reported more frequently and for complications regarding the meeting of joint arrangements with other teachers, which seemed to often be more problematic for secondary school teachers. The latter finding indicates that challenges associated with meeting arrangements with multiple teachers regarding CMS use might partly explain why secondary teachers employ effective CMS less often.

In line with the literature on using CMS within the general school context, lack of knowledge about interventions and insufficient knowledge transfer during undergraduate training were seldom identified as barriers to CMS implementation [36]. This finding, however, contradicts the results of this and previous studies showing associations between knowledge, training, and FoU [13-15,25]. Our results suggest that informing teachers about the importance of knowledge on interventions and training focused on ADHD should be one of the first steps toward bridging the science-practitioner gap.

Moreover, barriers reported in the present study have important implications for how CMS could become more sustainable for teachers by developing training modules that focus on using CMS. Such training sessions could include workshops addressingcommon barriers to CMS use to help teachers prepare for and overcome them. For instance, the meaning of time constraints (e.g., intervention implementation might initially appear time-consuming, but would probably save time in the long run thanks to its potential to minimize disturbing behaviors associated with ADHD), the benefits of CMS to all students, not just those with ADHD [59], or possibilities in improving the coordination and communication among colleagues could also be discussed. These descriptive results, however, should be interpreted with caution. As with variable class sizes, these perceived barriers do not necessarily influence the use of CMS. Future research is needed to confirm that these identified barriers have an actual impact on the use of CMS.

\subsection{Limitations}

While the current study significantly broadened our knowledge about factors related to the use of effective CMS from the teachers' perspectives, it has several limitations.

First and foremost, as our study results relied on a cross-sectional design, causal inferences should be drawn with caution. For example, while the assumption that more training on ADHD will enhance the use of effective CMS seems intuitively correct, it is equally possible that those teachers who use more effective CMS are also more apt to engage in formal or informal training activities. Intervention studies are necessary to clarify the question of causality.

Second, our study relied exclusively on teachers' self-reports of their CMS use, which may have resulted in inaccurate estimates of actual CMS use in an everyday school context. Future studies might consider using direct observation or an experimental paradigm to test whether the teachers' actual behavior is affected by the same variables as those in their self-reports.

Another measure-related limitation lies in the operationalization of training as a dichotomous variable. In our operationalization of the training variable, we did not consider the quality and quantity of the training received. Research on ADHD on the Internet was thus considered equal to attending a workshop or conference on CMS use in the present study, limiting the variable's informative value.

In addition, our measurement of effective CMS did not include all possible strategies. However, the CMS we did include were identified by the teachers themselves, and are 
consistent with well-established, evidence-based CMS for children with ADHD [5,6,48]; some of the most effective strategies (e.g., daily report cards; [6]) were not considered.

Volunteer responses have their own potential limitations. Teachers who completed our questionnaire might have been more interested in ADHD right from the start, making their answers differ from those of non-responders.

\section{Conclusions}

In conclusion, our study results suggest that improving teachers' perception of the effectiveness of a certain CMS, enabling them to participate in more ADHD-specialized training as well as addressing commonly perceived barriers in the scope of these trainings are potential leverage points to encourage effective CMS use and to result in sustainable improvement for students with ADHD. As a consequence, they provide an inclusive and effective learning environment for children with ADHD, in line with one of the sustainable development goals for education.

Author Contributions: M.-L.C., H.C. and M.Z. planned and conceived the study. A.S. and M.S. performed the analyses. A.S. and S.D. drafted the manuscript. That H.C. and M.Z. revised and commented on the manuscript. A.S. and S.D. finalized the manuscript and all co-authors provided feedback on this manuscript version. All authors have read and agreed to the published version of the manuscript.

Funding: This research was part of the project "ADHD in the classroom", which is part of the RTG 2271 and funded by the German Research Foundation (DFG) project number 290878970-GRK 2271, project 1 .

Institutional Review Board Statement: Ethical review and approval were waived for this study, due to specifications of the University of Marburg, since no vulnerable samples were examined, and the study does not violate the physical or psychological integrity, the right to privacy, or other subjective rights or the interests of the study participants.

Informed Consent Statement: Informed consent was obtained from all subjects involved in the study.

Data Availability Statement: The datasets are stored at the University of Marburg and can be accessed there.

Conflicts of Interest: The authors declare no conflict of interest.

\section{References}

1. American Psychiatric Association. Diagnostic and Statistical Manual of Mental Disorders, 5th ed.; American Psychiatric Publishing: Washington, DC, USA, 2013; ISBN 978-0-89042-555-8.

2. Frazier, T.W.; Youngstrom, E.A.; Glutting, J.J.; Watkins, M.W. ADHD and achievement: Meta-analysis of the child, adolescent, and adult literatures and a concomitant study with college students. J. Learn. Disabil. 2007, 40, 49-65. [CrossRef] [PubMed]

3. Loe, I.M.; Feldman, H.M. Academic and educational outcomes of children with ADHD. J. Pediatr. Psychol. 2007, 32, 643-654. [CrossRef] [PubMed]

4. van der Oord, S.; Prins, P.J.M.; Oosterlaan, J.; Emmelkamp, P.M.G. Efficacy of methylphenidate, psychosocial treatments and their combination in school-aged children with ADHD: A meta-analysis. Clin. Psychol. Rev. 2008, 28, 783-800. [CrossRef] [PubMed]

5. Gaastra, G.F.; Groen, Y.; Tucha, L.; Tucha, O. The Effects of Classroom Interventions on Off-Task and Disruptive Classroom Behavior in Children with Symptoms of Attention-Deficit/Hyperactivity Disorder: A Meta-Analytic Review. PLoS ONE 2016, 11, e0148841. [CrossRef]

6. DuPaul, G.J.; Eckert, T.L.; Vilardo, B. The Effects of School-Based Interventions for Attention Deficit Hyperactivity Disorder: A Meta-Analysis 1996-2010. Sch. Psych. Rev. 2012, 41, 387-412. [CrossRef]

7. United Nations Sustainable Development Goals Home Page. Available online: https://www.un.org/sustainabledevelopment/ education/ (accessed on 10 November 2021).

8. DuPaul, G.J.; Chronis-Tuscano, A.; Danielson, M.L.; Visser, S.N. Predictors of Receipt of School Services in a National Sample of Youth with ADHD. J. Atten. Disord. 2019, 23, 1303-1319. [CrossRef]

9. Ruhmland, M.; Christiansen, H. Konzepte zu Grundlagen von ADHS und Interventionen im Unterricht bei Grundschullehrkräften. Psychol. Erzieh. Unterr. 2017, 64, 109-122. [CrossRef]

10. Ajzen, I. Attitudes, Personality and Behaviour, 2nd ed.; Open University Press: Berkshire, UK, 2005; ISBN 978-0335217038.

11. Gollwitzer, M.; Thorwart, A.; Meissner, K. Editorial: Psychological Responses to Violations of Expectations. Front. Psychol. 2017, 8, 2357. [CrossRef] 
12. Rief, W.; Glombiewski, J.A.; Gollwitzer, M.; Schubö, A.; Schwarting, R.; Thorwart, A. Expectancies as core features of mental disorders. Curr. Opin. Psychiatry 2015, 28, 378-385. [CrossRef]

13. Strelow, A.E.; Dort, M.; Schwinger, M.; Christiansen, H. Influences on pre-service teachers' intention to use classroom management strategies for students with ADHD: A model analysis. Int. J. Educ. Res. 2020, 103, 101627. [CrossRef]

14. Strelow, A.E.; Dort, M.; Schwinger, M.; Christiansen, H. Influences on Teachers' Intention to Apply Classroom Management Strategies for Students with ADHD: A Model Analysis. Sustainability 2021, 13, 2558. [CrossRef]

15. Zemp, M.; Hehlke, L.; Strelow, A.E.; Dort, M.; Christiansen, H. Empirische Arbeit: Einstellung und Intention zum Einsatz (in)effektiver Klassenmanagement-Interventionen von Lehrpersonen und Lehramtsstudierenden bei Schüler*Innen mit ADHS: Eine Replikationsstudie. Psychol. Erzieh. Unterr. 2021, 68. [CrossRef]

16. Kaff, M.S.; Zabel, R.H.; Milham, M. Revisiting Cost-Benefit Relationships of Behavior Management Strategies: What Special Educators Say About Usefulness, Intensity, and Effectiveness. Prev. Sch. Fail. 2007, 51, 35-45. [CrossRef]

17. Mulligan, S. Classroom Strategies Used by Teachers of Students with Attention Deficit Hyperactivity Disorder. Phys. Occup. Ther. Pediatr. 2001, 20, 25-44. [CrossRef]

18. Gaastra, G.F.; Groen, Y.; Tucha, L.; Tucha, O. Unknown, Unloved? Teachers' Reported Use and Effectiveness of Classroom Management Strategies for Students with Symptoms of ADHD. Child Youth Care Forum 2020, 49, 1-22. [CrossRef]

19. DuPaul, G.J.; Jimerson, S.R. Assessing, understanding, and supporting students with ADHD at school: Contemporary science, practice, and policy. Sch. Psychol. Q. 2014, 29, 379-384. [CrossRef]

20. Harazni, L.; Alkaissi, A. The Experience of Mothers and Teachers of Attention Deficit/Hyperactivity Disorder Children, and Their Management Practices for the Behaviors of the Child a Descriptive Phenomenological Study. J. Educ. Pract. 2016, 7, 1-21.

21. Greene, R.W.; Beszterczey, S.K.; Katzenstein, T.; Park, K.; Goring, J. Are Students with ADHD More Stressful to Teach? J. Emot. Behav. Disord. 2002, 10, 79-89. [CrossRef]

22. Ward, R.J.; Bristow, S.J.; Kovshoff, H.; Cortese, S.; Kreppner, J. The Effects of ADHD Teacher Training Programs on Teachers and Pupils: A Systematic Review and Meta-Analysis. J. Atten. Disord. 2020. [CrossRef]

23. Latouche, A.P.; Gascoigne, M. In-Service Training for Increasing Teachers' ADHD Knowledge and Self-Efficacy. J. Atten. Disord. 2019, 23, 270-281. [CrossRef]

24. Vereb, R.L.; DiPerna, J.C. Teachers' Knowledge of ADHD, Treatments for ADHD, and Treatment Acceptability: An Initial Investigation. Sch. Psych. Rev. 2004, 33, 421-428. [CrossRef]

25. Aguiar, A.P.; Kieling, R.R.; Costa, A.C.; Chardosim, N.; Dorneles, B.V.; Almeida, M.R.; Mazzuca, A.C.; Kieling, C.; Rohde, L.A. Increasing teachers' knowledge about ADHD and learning disorders: An investigation on the role of a psychoeducational intervention. J. Atten. Disord. 2014, 18, 691-698. [CrossRef] [PubMed]

26. Hart, K.C.; Fabiano, G.A.; Evans, S.W.; Manos, M.J.; Hannah, J.N.; Vujnovic, R.K. Elementary and Middle School Teachers' Self-Reported Use of Positive Behavioral Supports for Children with ADHD: A National Survey. J. Emot. Behav. Disord. 2017, 25, 246-256. [CrossRef]

27. Mohr-Jensen, C.; Steen-Jensen, T.; Bang-Schnack, M.; Thingvad, H. What Do Primary and Secondary School Teachers Know About ADHD in Children? Findings from a Systematic Review and a Representative, Nationwide Sample of Danish Teachers. J. Atten. Disord. 2019, 23, 206-219. [CrossRef]

28. West, J.; Taylor, M.; Houghton, S.; Hudyma, S. A Comparison of Teachers' and Parents' Knowledge and Beliefs About AttentionDeficit/Hyperactivity Disorder (ADHD). Sch. Psychol. Int. 2005, 26, 192-208. [CrossRef]

29. Martinussen, R.; Tannock, R.; Chaban, P. Teachers' Reported Use of Instructional and Behavior Management Practices for Students with Behavior Problems: Relationship to Role and Level of Training in ADHD. Child Youth Care Forum 2011, 40, 193-210. [CrossRef]

30. Bussing, R.; Gary, F.A.; Leon, C.E.; Garvan, C.W.; Reid, R. General Classroom Teachers' Information and Perceptions of Attention Deficit Hyperactivity Disorder. Behav. Disord. 2002, 27, 327-339. [CrossRef]

31. OECD. Education at a Glance 2014: OECD Indicators; OECD Publishing: Paris, France, 2014; ISBN 978-92-64-21505-4.

32. Kos, J.M.; Richdale, A.L.; Jackson, M.S. Knowledge about Attention-Deficit/Hyperactivity Disorder: A comparison of in-service and preservice teachers. Psychol. Sch. 2004, 41, 517-526. [CrossRef]

33. Sniehotta, F.F.; Schwarzer, R.; Scholz, U.; Schüz, B. Action planning and coping planning for long-term lifestyle change: Theory and assessment. Eur. J. Soc. Psychol. 2005, 35, 565-576. [CrossRef]

34. Schwarzer, R. Modeling Health Behavior Change: How to Predict and Modify the Adoption and Maintenance of Health Behaviors. Appl. Psychol. 2008, 57, 1-29. [CrossRef]

35. Dort, M.; Strelow, A.E.; French, B.; Groom, M.; Luman, M.; Thorell, L.B.; Biele, G.; Christiansen, H. Bibliometric Review: Classroom Management in ADHD-Is There a Communication Gap Concerning Knowledge between the Scientific Fields Psychiatry/Psychology and Education? Sustainability 2020, 12, 6826. [CrossRef]

36. Long, A.C.J.; Hagermoser Sanetti, L.M.; Collier-Meek, M.A.; Gallucci, J.; Altschaefl, M.; Kratochwill, T.R. An exploratory investigation of teachers' intervention planning and perceived implementation barriers. J. Sch. Psychol. 2016, 55, 1-26. [CrossRef]

37. Bussing, R.; Koro-Ljungberg, M.; Gagnon, J.C.; Mason, D.M.; Ellison, A.; Noguchi, K.; Garvan, C.W.; Albarracin, D. Feasibility of School-Based ADHD Interventions: A Mixed-Methods Study of Perceptions of Adolescents and Adults. J. Atten. Disord. 2016, 20, 400-413. [CrossRef] [PubMed] 
38. Moore, D.A.; Gwernan-Jones, R.; Richardson, M.; Racey, D.; Rogers, M.; Stein, K.; Thompson-Coon, J.; Ford, T.J.; Garside, R. The experiences of and attitudes toward non-pharmacological interventions for attention-deficit/hyperactivity disorder used in school settings: A systematic review and synthesis of qualitative research. Emot. Behav. Diffic. 2016, 21, 61-82. [CrossRef]

39. Durlak, J.A.; DuPre, E.P. Implementation matters: A review of research on the influence of implementation on program outcomes and the factors affecting implementation. Am. J. Community Psychol. 2008, 41, 327-350. [CrossRef] [PubMed]

40. Budge, E.J.; Tsoti, S.M.; Howgate, D.J.; Sivakumar, S.; Jalali, M. Collective intelligence for translational medicine: Crowdsourcing insights and innovation from an interdisciplinary biomedical research community. Ann. Med. 2015, 47, 570-575. [CrossRef] [PubMed]

41. Wang, C.; Han, L.; Stein, G.; Day, S.; Bien-Gund, C.; Mathews, A.; Ong, J.J.; Zhao, P.-Z.; Wei, S.-F.; Walker, J.; et al. Crowdsourcing in health and medical research: A systematic review. Infect. Dis. Poverty 2020, 9, 8. [CrossRef] [PubMed]

42. Beck, S.; Bergenholtz, C.; Bogers, M.; Brasseur, T.-M.; Conradsen, M.L.; Di Marco, D.; Distel, A.P.; Dobusch, L.; Dörler, D.; Effert, A.; et al. The Open Innovation in Science research field: A Collaborative Conceptualisation Approach. Ind. Innov. 2020, 1-50. [CrossRef]

43. Blackburn, S.; McLachlan, S.; Jowett, S.; Kinghorn, P.; Gill, P.; Higginbottom, A.; Rhodes, C.; Stevenson, F.; Jinks, C. The extent, quality and impact of patient and public involvement in primary care research: A mixed methods study. Res. Involv. Engagem. 2018, 4, 16. [CrossRef]

44. Brett, J.; Staniszewska, S.; Mockford, C.; Herron-Marx, S.; Hughes, J.; Tysall, C.; Suleman, R. Mapping the impact of patient and public involvement on health and social care research: A systematic review. Health Expect. 2014, 17, 637-650. [CrossRef]

45. Sherman, J.; Rasmussen, C.; Baydala, L. The impact of teacher factors on achievement and behavioural outcomes of children with Attention Deficit/Hyperactivity Disorder (ADHD): A review of the literature. Educ. Res. 2008, 50, 347-360. [CrossRef]

46. Statista. Frauenanteil unter den Lehrkräften nach Schulart. 2021. Available online: https://de.statista.com/statistik/daten/ studie/1129852/umfrage/frauenanteil-unter-den-lehrkraeften-in-deutschland-nach-schulart/ (accessed on 27 October 2021).

47. Leiner, D. SoSci Survey, Version 3.1. 06; SoSci Survey GmbH: München, Germany, 2019.

48. Kos, J.M.; Richdale, A.L.; Hay, D.A. Children with Attention Deficit Hyperactivity Disorder and Their Teachers: A Review of the Literature. Intl. J. Disabil. Dev. Educ. 2006, 53, 147-160. [CrossRef]

49. IBM Corp. IBM SPSS Statistics for Windows, Version 25; IBM SPSS Corp.: Armonk, NY, USA, 2017.

50. Muthén, L.K.; Muthén, B. Mplus User's Guide: Statistical Analysis with Latent Variables, User's Guide; Muthén \& Muthén: Los Angeles, CA, USA, 2017.

51. Leiner, D.J. Too Fast, Too Straight, Too Weird: Non-Reactive Indicators for Meaningless Data in Internet Surveys. Surv. Res. Methods 2019, 13, 229-248. [CrossRef]

52. Enders, C.K. The Performance of the Full Information Maximum Likelihood Estimator in Multiple Regression Models with Missing Data. Educ. Psychol. Meas. 2001, 61,713-740. [CrossRef]

53. Barbeau, K.; Boileau, K.; Sarr, F.; Smith, K. Path analysis in Mplus: A tutorial using a conceptual model of psychological and behavioral antecedents of bulimic symptoms in young adults. Quant. Methods Psychol. 2019, 15, 38-53. [CrossRef]

54. Akaike, H. A new look at the statistical model identification. IEEE Trans. Automat. Contr. 1974, 19, 716-723. [CrossRef]

55. Schwarz, G. Estimating the Dimension of a Model. Ann. Stat. 1978, 6, 461-464. [CrossRef]

56. Huang, P.-H. Asymptotics of AIC, BIC, and RMSEA for Model Selection in Structural Equation Modeling. Psychometrika 2017, 82, 407-426. [CrossRef] [PubMed]

57. Alkahtani, K.D.F. Teachers' Knowledge and Misconceptions of Attention Deficit/Hyperactivity Disorder. Psychology 2013, 4, 963-969. [CrossRef]

58. Falk, C.F.; Muthukrishna, M. Parsimony in model selection: Tools for assessing fit propensity. Psychol. Methods 2021. Advance online publication. [CrossRef]

59. Epstein, M.; Atkins, M.; Cullinan, D.; Kutash, K.; Weaver, R. Reducing Behavior Problems in the Elementary School Classroom: A Practice Guide (NCEE \#2008-012); Institute of Education Sciences: Washington, DC, USA, 2008. 